\title{
Article \\ Carbon Monoxide Poisoning and Developing Ischemic Heart Disease: A Nationwide Population-Based Nested Case-Control Study
}

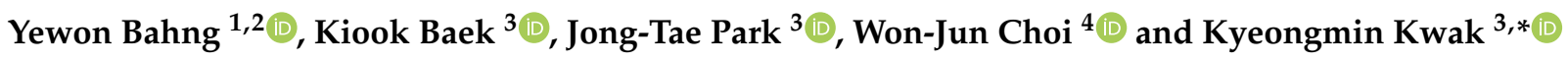 \\ 1 Department of Environmental Health Sciences, Graduate School of Public Health, Seoul National University, \\ Seoul 00826, Korea; jupiterwalker@snu.ac.kr \\ 2 Department of Occupational and Environmental Medicine, Gyeonggi Provincial Medical Center Suwon \\ Hospital, Suwon 16316, Korea \\ 3 Department of Occupational and Environmental Medicine, Korea University Ansan Hospital, \\ Ansan 15355, Korea; bko8899@gmail.com (K.B.); impjt@korea.ac.kr (J.-T.P.) \\ 4 Department of Occupational and Environmental Medicine, Gil Medical Center, Gachon University College of \\ Medicine, Incheon 21565, Korea; wjchoi@gachon.ac.kr \\ * Correspondence: pathfinder81@korea.ac.kr
}

Citation: Bahng, Y.; Baek, K.; Park, J.-T.; Choi, W.-J.; Kwak, K. Carbon Monoxide Poisoning and Developing Ischemic Heart Disease: A Nationwide Population-Based Nested Case-Control Study. Toxics 2021, 9 , 239. https://doi.org/10.3390/ toxics 9100239

Academic Editor: Peter Franklin

Received: 21 August 2021

Accepted: 20 September 2021

Published: 28 September 2021

Publisher's Note: MDPI stays neutral with regard to jurisdictional claims in published maps and institutional affiliations.

Copyright: (c) 2021 by the authors. Licensee MDPI, Basel, Switzerland. This article is an open access article distributed under the terms and conditions of the Creative Commons Attribution (CC BY) license (https:/ / creativecommons.org/licenses/by/ $4.0 /)$.

\begin{abstract}
Although there are several case reports showing that carbon monoxide (CO) poisoning causes ischemic heart disease (IHD), no large-scale epidemiological studies have shown a significant association between the two. To investigate the association between $\mathrm{CO}$ poisoning and IHD, a nested case-control study of 28,113 patients who experienced CO poisoning and 28,113 controls matched by sex and age was performed using the nationwide health database of South Korea. Based on a conditional logistic regression, there was a significantly higher risk of IHD among the CO poisoning group than among the control group (adjusted hazard ratio [HR], 2.16; 95\% confidence interval [CI], 1.87-2.49). The risk of IHD after $\mathrm{CO}$ poisoning was higher among the younger age group under 40 years (adjusted $\mathrm{HR}, 4.85 ; 95 \% \mathrm{CI}, 3.20-7.35$ ), and it was much greater among those with comorbidities (adjusted HR, 10.69; 95\% CI, 2.41-47.51). The risk of IHD was the highest within the first two years after CO poisoning (adjusted HR, 11.12; 95\% CI, 4.54-27.22). Even if more than six years had passed, the risk was still significantly higher than among the control group (adjusted HR, $1.55 ; 95 \% \mathrm{CI}, 1.27-1.89)$. The analyses imply that $\mathrm{CO}$ poisoning is associated with an increased risk of IHD.
\end{abstract}

Keywords: carbon monoxide; $\mathrm{CO}$ poisoning; $\mathrm{CO}$ intoxication; ischemic heart disease; coronary heart disease; cardiac dysfunction; toxic effect; big data; nationwide health database

\section{Introduction}

Carbon monoxide $(\mathrm{CO})$ poisoning can occur from brief exposure to $\mathrm{CO}$ at excessive levels or from longer exposures at lower levels [1]. The clinical symptoms of CO poisoning are mostly nonspecific and depend on the exposure duration and $\mathrm{CO}$ levels [2]. CO poisoning symptoms mainly include neurological symptoms, such as dizziness, nausea, weakness, headaches, lethargy, and confusion [3,4]. CO binds to hemoglobin with a higher affinity than oxygen. By interfering with oxygen binding, it induces tissue hypoxia, which is thought to affect the organs that heavily depend on oxygen utilization, including the cardiovascular system [5]. In a study by Satran et al., 37\% of 230 patients with moderate to severe CO poisoning from 1994 to 2002 had a myocardial injury with ischemic electrocardiogram changes and elevated cardiac biomarkers [6,7]. When this patient group was followed up until 2005, the hazard ratio (HR) of long-term mortality was significantly higher in the group with myocardial infarction (MI) at 2.1 (95\% confidence interval [CI], 1.2-3.7) compared to the group without MI [8]. Additionally, there have been reports of MI after CO poisoning [9-11], and among them, there were cases that occurred at low 
exposure levels [11]. Therefore, the possibility that the risk of ischemic heart disease (IHD) may increase due to $\mathrm{CO}$ poisoning can be considered. However, only a few case reports have confirmed the effects of $\mathrm{CO}$ toxicity on the cardiovascular system. Moreover, in a large epidemiological study performed in Taiwan based on a nationwide health database, no increased risk of IHD was found [12]. No large-scale epidemiological studies have explored the relationship between CO poisoning and IHD development other than the study in Taiwan. Therefore, further epidemiological research is needed.

In this study, a nested case-control study was performed using the nationwide health database of South Korea to confirm the association between CO poisoning and IHD risk.

\section{Materials and Methods}

\subsection{Data Source}

The National Health Insurance Database (NHID) of South Korea was used to construct a retrospective cohort for a nested case-control study of data from 2002 to 2017. The NHID was established by the National Health Insurance Service in 2002 and covers the entire Korean population. It contains data on healthcare utilization, sociodemographic variables, health screenings, and mortality [13]. The data on the causes of death, which were provided by Statistics Korea (KoSTAT) and linked to the NHID, were also used.

\subsection{Study Population}

CO poisoning was classified by the International Classification of Diseases, 10th revision (ICD-10) code T58, and all patients treated more than once from 2002 to 2017 were selected as the case group. Controls were also randomly selected among those for whom $\mathrm{CO}$ poisoning had not been diagnosed during the same period, and they were matched by sex and age to the case group at a 1:1 ratio. Initially, 29,357 patients and 29,357 controls were included. Among them, 224 cases diagnosed with IHD (I20-I25) prior to enrollment in this study and 224 matched subjects were excluded. Since the NHID was established in 2002 and does not include data from previous years, 2002 was considered a wash-out period, and 359 cases and 359 controls registered in that year were excluded. Additionally, those with errors in the date of death (i.e., those who had medical records after the date of death) were excluded, so three cases and three controls were excluded. Detailed morbidity codes were not provided by KoSTAT because mortality statistics for cases with ICD-10 code T58 are considered sensitive information. Instead, those who died with "toxic effects of substances chiefly nonmedicinal as to source (T51-T65)" within three months of CO poisoning were presumed to have died directly from it. If no information was provided on the cause of death, those who died within two weeks of $\mathrm{CO}$ poisoning were presumed to have died from it. These 660 cases of suspected direct death from CO poisoning and 660 matched controls were excluded. Thus, the final study participants consisted of 28,113 CO poisoning cases and 28,113 matched controls (Figure 1).

\subsection{Definition of Study Outcomes and Comorbidities}

Cases of IHD were defined as those who received treatment more than those with ICD10 codes I20-I25, including at least one inpatient care code. Diabetes mellitus (DM) (E10E14), hypertension (I10-I15), dyslipidemia (E78), atrial fibrillation (AF) (I48), congestive heart failure (CHF) (I50), hemorrhagic stroke (I60-I62), and ischemic stroke (I63-I69) were defined as comorbidities. DM, hypertension, dyslipidemia, AF, and CHF were diagnosed for patients who received the treatment more than twice with their corresponding ICD-10 codes, while hemorrhagic and ischemic stroke were diagnosed for patients who received the treatment more than once with their corresponding ICD-10 codes. 


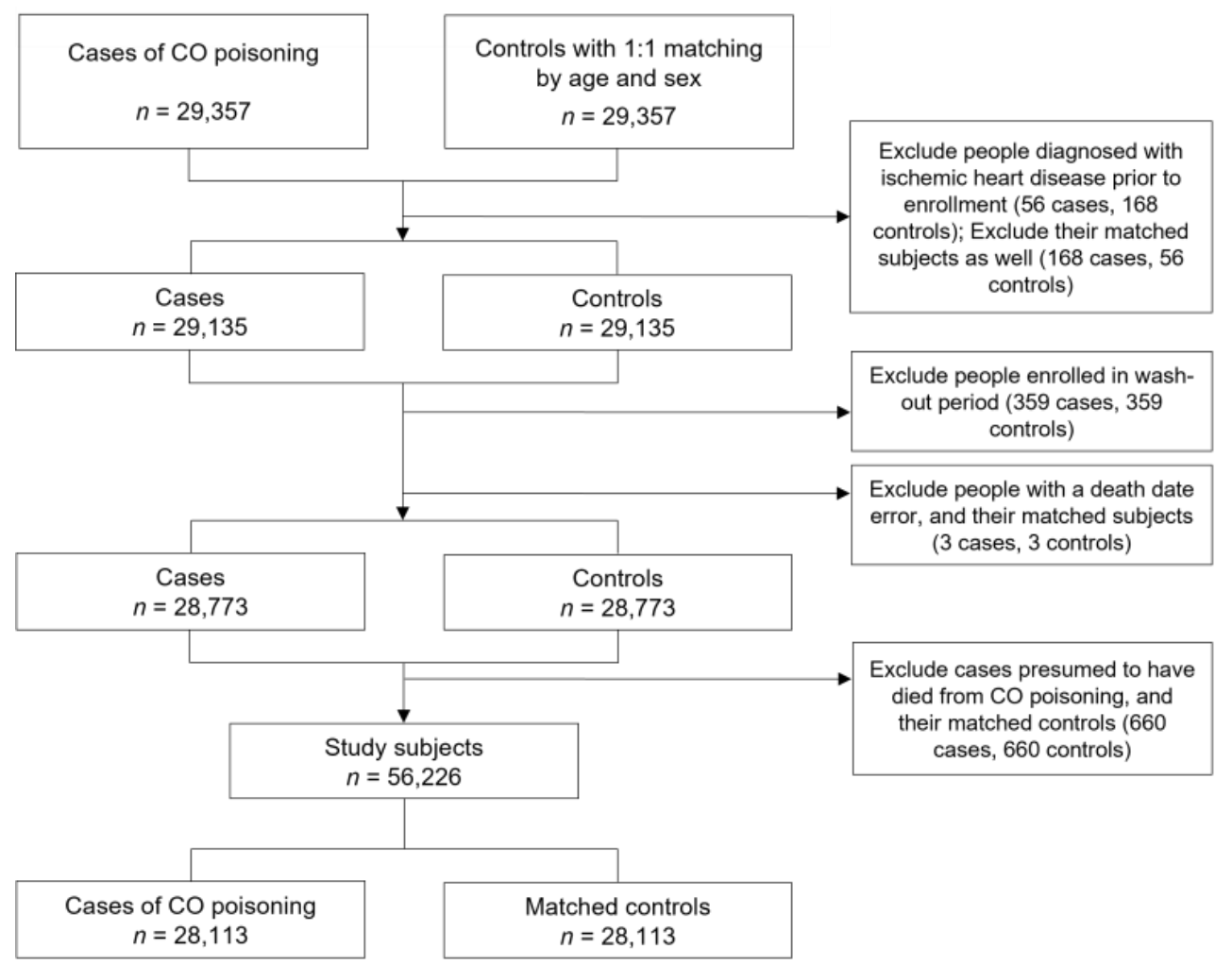

Figure 1. Flowchart for the selection of the study population.

\subsection{Covariates}

The NHID includes information on socioeconomic factors. Study subject age at the time of enrollment in this study was considered. Residential areas were divided into Seoul, metropolitan cities other than Seoul, and other regions. Household income was classified as high (top 30\%), middle, and low (bottom 30\%) based on financial contributions to health insurance. Although the NHID's national health screening database contains information about health behaviors, such as smoking, drinking, and exercise, nearly $40 \%$ of the study subjects never had a national health checkup, so much of the information on health behaviors was missing. Information about health behaviors was not used as a covariate because using it with many missing values could affect the results.

\subsection{Statistical Analysis}

Descriptive analyses of sociodemographic characteristics (sex, age, household income, and residential area), comorbidities, and IHD incidence were performed for the CO poisoning and control groups. Chi-square tests were conducted to assess the differences in household income status, the distribution of residential areas, the prevalence of comorbidities, and the incidence of IHD between the CO poisoning and control groups. The incidence rate of IHD was calculated in both the case and control groups, and the incidence rates of CHD according to age group, sex, residential area, household income, and comorbidities were also calculated. Using a conditional logistic regression model, crude and adjusted (i.e., adjusted for residential area, household income, and comorbidities) HRs and their corresponding 95\% CIs for IHD development were calculated. Cumulative incidence was also compared between $\mathrm{CO}$ poisoning and control groups using a reverse Kaplan-Meier survival curve with a log-rank test [14]. Moreover, crude and adjusted HRs and their corresponding $95 \%$ CIs for the CO poisoning and control groups were calculated using stratification according to covariates and follow-up periods. All statistical analyses were conducted using SAS version 9.4 (SAS Institute, Cary, NC, USA). 


\section{Results}

\subsection{Baseline Characteristics of the Subjects}

The average age of the study subjects was 37.4 years. Most subjects $(36.4 \%)$ were aged $40-65$ years, followed by those aged $25-39$ years $(32.9 \%),<25$ years $(23.5 \%)$, and $\geq 65$ years $(7.2 \%)$. There were more men (54.8\%) than women. The sex and age distributions among the $\mathrm{CO}$ poisoning and control groups were matched. As for the residential area, the proportion of subjects living in Seoul was higher among the control group $(20.4 \%)$, while the proportion of subjects living in areas other than metropolitan cities, including Seoul, was higher among the CO poisoning group (59.6\%). As for the household income level, the proportion of subjects belonging to the high-income group was higher among the control group (36.2\%), while the proportion of subjects belonging to the low-income group was higher among the $\mathrm{CO}$ poisoning group $(31.6 \%)$. When considering comorbidities, there were no significant differences in the prevalence of hypertension and AF between the CO poisoning and control groups. The prevalence rates of DM, dyslipidemia, CHF, and hemorrhagic stroke were significantly higher in the $\mathrm{CO}$ poisoning group, while the prevalence of ischemic stroke was significantly higher in the control group (Table 1).

Table 1. General characteristics of the subjects.

\begin{tabular}{|c|c|c|c|}
\hline Characteristics & $\begin{array}{l}\text { Carbon Monoxide Poisoning } \\
\qquad n=28,113\end{array}$ & $\begin{array}{c}\text { Control } \\
n=28,113\end{array}$ & $p$-Value \\
\hline Mean age (years) * & $37.4 \pm 17.6$ & $37.4 \pm 17.6$ & 1.000 \\
\hline Age (years) ${ }^{\dagger}$ & & & 1.000 \\
\hline$<25$ & $6600(23.5 \%)$ & $6600(23.5 \%)$ & \\
\hline $25-39$ & $9429(32.9 \%)$ & $9429(32.9 \%)$ & \\
\hline $40-64$ & $10,247(36.4 \%)$ & $10,247(36.4 \%)$ & \\
\hline$\geq 65$ & $2017(7.2 \%)$ & $2017(7.2 \%)$ & \\
\hline $\operatorname{Sex}^{+}$ & & & 1.000 \\
\hline Male & $15,417(54.8 \%)$ & $15,417(54.8 \%)$ & \\
\hline Female & $12,696(45.2 \%)$ & $12,696(45.2 \%)$ & \\
\hline Residential area $^{\dagger}$ & & & $<0.001$ \\
\hline Seoul & $4616(16.4 \%)$ & $5738(20.4 \%)$ & \\
\hline Other metropolitan cities & $6745(24.0 \%)$ & $6841(24.3 \%)$ & \\
\hline Other areas & $16,752(59.6 \%)$ & $15,534(55.3 \%)$ & \\
\hline Household income $^{\dagger}$ & & & $<0.001$ \\
\hline High & $8192(29.1 \%)$ & $10,169(36.2 \%)$ & \\
\hline Middle & $11,042(39.4 \%)$ & $10,650(37.9 \%)$ & \\
\hline Low & $8879(31.6 \%)$ & $7294(25.9 \%)$ & \\
\hline \multicolumn{4}{|l|}{ Comorbidity $^{+}$} \\
\hline Hypertension & $2314(8.3 \%)$ & $2386(8.5 \%)$ & 0.273 \\
\hline Diabetes & $2223(7.9 \%)$ & $1788(6.4 \%)$ & $<0.001$ \\
\hline Dyslipidemia & $4875(17.3 \%)$ & $4045(14.4 \%)$ & $<0.001$ \\
\hline Atrial fibrillation & $127(0.2 \%)$ & $69(0.3 \%)$ & 0.329 \\
\hline Congestive heart disease & $187(0.7 \%)$ & $95(0.3 \%)$ & $<0.001$ \\
\hline Hemorrhagic stroke & $259(0.9 \%)$ & $77(0.3 \%)$ & $<0.001$ \\
\hline Ischemic stroke & $329(1.2 \%)$ & $431(1.5 \%)$ & $<0.001$ \\
\hline
\end{tabular}

${ }^{*}$ Values are presented as mean \pm standard deviation. ${ }^{+}$Values are presented as number of subjects $(\%)$.

\subsection{Risk of Developing Ischemic Heart Disease}

From 2003 to 2017, the number of cases with IHD among the CO poisoning and control groups were 729 and 386, respectively. The risk of developing IHD was significantly higher for the $\mathrm{CO}$ poisoning group than the control group by approximately 2.2 times (crude $\mathrm{HR}, 2.19 ; 95 \% \mathrm{CI}, 1.91-2.51$ ). The risk was significantly higher for the case group than in control group, even after adjusting for residential area, household income, and the presence or absence of comorbidities (adjusted HR, 2.16; 95\% CI, 1.87-2.49) (Table 2). The reverse 
Kaplan-Meier survival curves showed that the cumulative incidence of IHD over time was consistently significantly higher among the $\mathrm{CO}$ poisoning group than among the control group (log-rank test: $p<0.001$; Figure 2).

Table 2. Incidence rates and hazard ratios for ischemic heart disease among the CO poisoning and control groups.

\begin{tabular}{|c|c|c|c|c|c|}
\hline \multirow{2}{*}{ Groups } & \multirow{2}{*}{ No. of Cases } & \multirow{2}{*}{ Person-Years } & \multirow{2}{*}{$\begin{array}{l}\text { Incidence, per } \\
1000 \text { Person-Years }\end{array}$} & \multicolumn{2}{|c|}{$H R *(95 \%$ CI $)$} \\
\hline & & & & Crude & Adjusted $^{\dagger}$ \\
\hline Control & 386 & $125,466.7$ & 3.08 & 1.00 & 1.00 \\
\hline $\begin{array}{l}\text { Carbon monoxide } \\
\text { poisoning }\end{array}$ & 729 & $128,860.3$ & 5.66 & $2.19(1.91-2.51)$ & $2.16(1.87-2.49)$ \\
\hline
\end{tabular}

${ }^{*} \mathrm{HR}$, hazard ratio. ${ }^{\dagger}$ Adjusted for residential area, household income, and presence or absence of comorbidities.

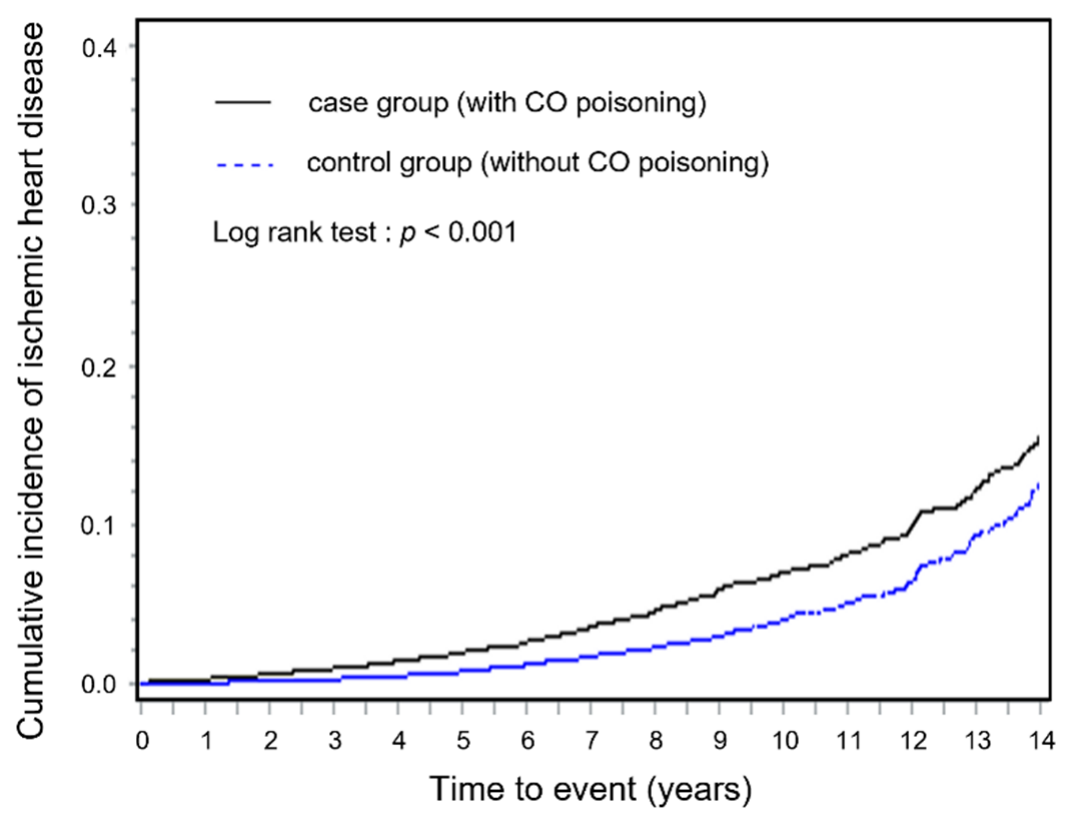

Figure 2. Comparison of cumulative incidence rates among the $\mathrm{CO}$ poisoning and control groups.

When analyzed by stratification according to socioeconomic factors, the risk of developing IHD among the CO poisoning group compared with the control group was similar in men and women. The risk of developing IHD among the $\mathrm{CO}$ poisoning group was much higher for the younger age group (<40 years) (adjusted HR, 4.85; 95\% CI, 3.20-7.35), and no significantly increased risk was found for patients aged $\geq 65$ years (adjusted HR, 1.15; 95\% CI, 0.87-1.51). The risk of developing IHD among the CO poisoning group was the highest for those living in metropolitan areas, except Seoul (adjusted HR, 3.69; 95\% CI, 1.79-7.61), while those living in Seoul did not show any significant increase in risk (adjusted HR, 1.25; 95\% CI, 0.53-2.95). Based on household income levels, there was a significantly increased risk of developing IHD among the $\mathrm{CO}$ poisoning group for all household income deciles, but the effect size of the risk for the high-income group was relatively low. When stratified according to comorbidities, the risk of developing IHD among the CO poisoning group was higher for those with comorbidities (crude HR, 3.00; 95\% CI, 1.67-5.38), and this risk was even greater when the model adjusted for covariates (adjusted HR, 10.69; 95\% CI, 2.41-47.51) (Table 3). 
Table 3. Incidence rates and hazard ratios of ischemic heart disease as stratified by sex, age, residential area, household income, and comorbidities.

\begin{tabular}{|c|c|c|c|c|c|c|c|c|}
\hline \multirow[b]{2}{*}{ Variables } & \multicolumn{3}{|c|}{ Carbon Monoxide Poisoning } & \multicolumn{3}{|c|}{ Control } & \multicolumn{2}{|c|}{$\mathrm{HR}^{*}(95 \% \mathrm{CI})^{\dagger}$} \\
\hline & $\begin{array}{l}\text { No. of } \\
\text { Cases }\end{array}$ & Person-Years & Incidence & $\begin{array}{l}\text { No. of } \\
\text { Cases }\end{array}$ & Person-Years & Incidence & Crude & Adjusted $\ddagger$ \\
\hline \multicolumn{9}{|c|}{ Sex } \\
\hline Male & 417 & $65,330.5$ & 6.38 & 217 & $67,597.7$ & 3.21 & $2.24(1.86-2.67)$ & $2.18(1.81-2.63)$ \\
\hline Female & 312 & $60,136.2$ & 5.19 & 169 & $61,262.6$ & 2.76 & $2.15(1.74-2.65)$ & $2.17(1.73-2.71)$ \\
\hline \multicolumn{9}{|c|}{ Age (years) } \\
\hline$<40$ & 166 & $71,042.7$ & 2.34 & 38 & $72,273.6$ & 0.53 & $4.69(3.25-6.75)$ & $4.85(3.20-7.35)$ \\
\hline $40-64$ & 371 & $44,444.6$ & 8.35 & 175 & $45,992.6$ & 3.80 & $2.37(1.95-2.87)$ & $2.27(1.85-2.78)$ \\
\hline$\geq 65$ & 192 & 9979.4 & 19.24 & 173 & $10,613.2$ & 16.30 & $1.28(0.97-1.58)$ & $1.15(0.87-1.51)$ \\
\hline \multicolumn{9}{|c|}{ Residential area } \\
\hline Seoul & 88 & $21,793.9$ & 4.04 & 80 & $31,035.1$ & 2.58 & $1.33(0.63-2.82)$ & $1.25(0.53-2.95)$ \\
\hline $\begin{array}{c}\text { Other } \\
\text { metropolitan } \\
\text { cities }\end{array}$ & 143 & $28,120.8$ & 5.09 & 86 & $32,434.9$ & 2.65 & $3.33(1.75-6.35)$ & $3.69(1.79-7.61)$ \\
\hline Other areas & 498 & $75,552.0$ & 6.59 & 220 & $65,390.2$ & 3.36 & $2.09(1.67-2.60)$ & $2.15(1.70-2.72)$ \\
\hline \multicolumn{9}{|c|}{ House income } \\
\hline High & 196 & $36,389.4$ & 5.39 & 150 & $46,260.0$ & 3.24 & $1.90(1.29-2.80)$ & $1.99(1.30-3.05)$ \\
\hline Middle & 270 & $48,954.8$ & 5.52 & 125 & $47,343.6$ & 2.64 & $2.69(1.82-3.96)$ & $2.75(1.82-4.15)$ \\
\hline Low & 263 & $40,122.5$ & 6.55 & 111 & $35,256.7$ & 3.15 & $2.83(1.76-4.55)$ & $2.64(1.58-4.38)$ \\
\hline \multicolumn{9}{|c|}{ Comorbidity } \\
\hline No & 520 & $105,695.0$ & 4.92 & 300 & $110,784.5$ & 2.71 & $2.12(1.78-2.53)$ & $2.05(1.73-2.44)$ \\
\hline Yes & 209 & $19,717.7$ & 10.57 & 86 & $18,075.9$ & 4.76 & $3.00(1.67-5.38)$ & $10.69(2.41-47.51)$ \\
\hline
\end{tabular}

${ }^{*}$ HR, hazard ratio. ${ }^{\dagger}$ The HR indicates the level of risk among the CO poisoning group compared with that of the control group. ${ }^{\ddagger}$ Adjusted for residential area, household income, and the presence or absence of comorbidities.

When stratified according to follow-up periods, the risk of developing IHD associated with $\mathrm{CO}$ poisoning was increased by approximately 5.2 times within two years of $\mathrm{CO}$ poisoning (crude HR, 5.24; 95\% CI, 3.12-8.80), and this risk was much greater-by 11 timesafter the model adjustment for other covariates (adjusted HR, 11.12; 95\% CI, 4.54-27.22). After more than two years of CO poisoning, the risk of developing IHD decreased, but it showed a consistent and significant increase when compared to the control group. Even after $\geq 6$ years, the risk was increased by $\geq 1.5$ times (adjusted HR, 1.55; 95\% CI, 1.27-1.89) (Table 4).

Table 4. Incidence and hazard ratios of ischemic heart disease as stratified by follow-up period.

\begin{tabular}{|c|c|c|c|c|c|c|c|c|}
\hline \multirow{2}{*}{$\begin{array}{l}\text { Follow-Up } \\
\text { Periods }\end{array}$} & \multicolumn{3}{|c|}{ Carbon Monoxide Poisoning } & \multicolumn{3}{|c|}{ Control } & \multicolumn{2}{|c|}{$\mathrm{HR}^{*}(95 \% \mathrm{CI})^{\dagger}$} \\
\hline & $\begin{array}{l}\text { No. of } \\
\text { Cases }\end{array}$ & Person-Years & Incidence & $\begin{array}{c}\text { No. of } \\
\text { Cases }\end{array}$ & Person-Years & Incidence & Crude & Adjusted $\ddagger$ \\
\hline$\leq 2$ & 130 & 7747.3 & 16.78 & 19 & 7372.4 & 2.58 & $5.24(3.12-8.80)$ & $11.12(4.54-27.22)$ \\
\hline$\overline{2}-4$ & 131 & $22,208.7$ & 5.90 & 59 & $22,273.5$ & 2.65 & $2.13(1.51-3.00)$ & $2.15(1.44-3.20)$ \\
\hline $4-6$ & 122 & $25,064.0$ & 4.87 & 71 & $25,985.3$ & 2.73 & $2.23(1.58-3.15)$ & $2.72(1.80-4.13)$ \\
\hline$>6$ & 346 & $70,446.6$ & 4.91 & 237 & $73,229.1$ & 3.24 & $1.64(1.36-1.98)$ & $1.55(1.27-1.89)$ \\
\hline
\end{tabular}

${ }^{*} \mathrm{HR}$, hazard ratio. ${ }^{+}$The HR indicates the level of risk among the CO poisoning group compared with that of the control group. ${ }^{\ddagger}$ Adjusted for residential area, household income, and the presence or absence of comorbidities.

\section{Discussion}

The effect of CO poisoning on the development of IHD was analyzed using data from the nationwide health database of South Korea. The results indicate that there is a significant association between $\mathrm{CO}$ poisoning and an increased risk of developing IHD. This study excluded patients who died directly from CO poisoning and confirmed that the long-term risk of IHD was significantly elevated. In particular, the level of risk was high in the younger age group, and it was confirmed that the risk of developing IHD was much greater in the presence of comorbidities related to IHD. 
Only limited studies have been conducted to evaluate the associations between $\mathrm{CO}$ poisoning and the risk of developing IHD. Although subsequent MIs have been reported several times after $\mathrm{CO}$ poisoning has occurred [9-11], it is not known whether the risk increases with time. The risk of ischemic stroke in the $\mathrm{CO}$ poisoning group was previously analyzed using the NHID. The results showed a significant 2.3-fold increase in risk, similar to the results of this study [15]. Ischemic stroke and IHD have common risk factors, and there are some similarities in the mechanisms of their development. Therefore, it is reasonable to approach IHD development caused by $\mathrm{CO}$ poisoning based on the common mechanism of ischemic stroke and IHD. Both ischemic stroke and IHD have atherothrombosis as an etiological factor. Exposure to $\mathrm{CO}$ enhances coagulation by binding to a fibrinogen-bound heme, which may lead to thromboembolism [16-18]. Several epidemiological studies and case reports have confirmed the prothrombic potential of $\mathrm{CO}$ exposure to IHD $[9,10,19,20]$. Thromboembolism not only directly causes IHD but may also increase the long-term risk of developing IHD. A study using Taiwan's nationwide health database also found a significantly increased long-term risk of cardiovascular events, including IHD, in patients with thromboembolism [21]. This CO-induced thromboembolism is the main mechanism that causes IHD in the early stages, and it can also increase the long-term risk of developing IHD, although this risk decreases with time.

The nationwide health database in Taiwan was also used to analyze the risk of cardiovascular disease, including IHD, in patients with CO poisoning from 2000 to 2011 [12]. The analysis revealed an elevated risk of developing IHD among patients with $\mathrm{CO}$ poisoning, with an adjusted HR of 1.14. This elevated risk was not significant (95\% CI, 0.93-1.40). However, considering that the HR was significantly higher at 1.75 (95\% CI, 1.06-2.89) for the group with severe $\mathrm{CO}$ poisoning and that the risk of IHD occurrence within 3 years was significant (HR, 1.33; 95\% CI, 1.00-1.76), the results of the Taiwanese study cannot rule out increased IHD risk due to $\mathrm{CO}$ poisoning. Various reasons for differing results between our study and the Taiwanese study can be considered. The population of South Korea is more than twice that of Taiwan, and our study had a slightly longer follow-up period than the Taiwanese study; therefore, the number of patients with CO poisoning was much greater in our study. In addition, our study performed 1:1 matching, and the Taiwanese study matched four-fold controls; thus, the composition of the control group may be different. Moreover, we used conditional logistic regression because our study was designed as a nested case-control study [22,23], but the study in Taiwan was analyzed using Cox's proportional hazard regression model. It is thought that these differences in the number of patients, control group composition, and statistical methods may have yielded different results. In addition to these demographic and methodological differences, other factors potentially influencing the occurrence of IHD may differ, further yielding differing outcomes. Lastly, clinical case management after $\mathrm{CO}$ poisoning may be different, allowing for different effects on IHD risk. However, no difference in $\mathrm{CO}$ poisoning case management was confirmed because this information was not provided by the nationwide health database.

Another mechanism by which CO poisoning may increase the risk of IHD is through the development of arrhythmias, including AF. Hypoxia and cardiac dysfunction caused by CO poisoning can induce paroxysmal tachycardia, paroxysmal ventricular tachycardia, ventricular fibrillation or flutter, and atrial fibrillation or flutter [12,24]. AF is known to be a risk factor for IHD and ischemic stroke $[25,26]$. It was hypothesized that the induction of arrhythmias, including AF, may play a role in increasing the long-term risk of IHD.

In this study, more than $60 \%$ of cases of $\mathrm{CO}$ poisoning occurred in younger patients under 40 years of age. The risk of developing IHD after experiencing CO poisoning in the younger age group ( $<40$ years) was much higher than that in other age groups. The higher the age group, the lower the risk of IHD after CO poisoning. In our analysis, no significant increase in risk was found in patients over 65 years of age. While there are several risk factors related to the occurrence of IHD in the elderly group, the incidence of IHD in the younger age group was not high, and the related risk factors were less prevalent among the 
younger age group than in the elderly group, which was thought to be due to the strong effect of $\mathrm{CO}$ exposure.

Regarding comorbidities, patients with underlying diseases related to IHD, such as hypertension, $\mathrm{DM}$, dyslipidemia, $\mathrm{CHF}, \mathrm{AF}$, and stroke, had a higher risk of developing IHD after CO poisoning than those without. When the residence and income levels were adjusted, it was confirmed that the risk in the presence of comorbidities was significantly higher than that in the control group. This suggests that hypoxemia, cardiac dysfunction, and thromboembolism after $\mathrm{CO}$ exposure more sensitively affect people with underlying heart disease-related comorbidities, which may increase the risk of developing IHD.

This study has several limitations. First, there are questions about the validity of the diagnosis of IHD. Because the NHID contains claims data, there are cases where a diagnosis code was only entered for the purpose of a claim, and diagnostic validity based on the ICD code is always doubtful because of these factors. Here, an operational definition of the disease was made to correct for these limitations, but we could not completely solve this problem. In addition, the NHID did not include radiographic images or laboratory data, and the information about health behaviors was not utilized because nearly $40 \%$ of the subjects' information was missing. There are limitations among the complete retrospective cohort due to the insufficient information provided for clinical records and health behaviors. Next, although the controls were randomly selected through the matching of their sex and age at a 1:1 ratio, there is a possibility that the case and control groups for the risk factors of IHD are not uniform, so bias might occur. Finally, the number of $\mathrm{CO}$ poisoning cases was relatively small before 2010, even if the recent increase in CO poisoning cases was considered. There is a high possibility that $\mathrm{CO}$ poisoning cases were omitted from the NHID before 2010, and it is possible that the results may be biased due to such omissions.

Despite these limitations, this study is meaningful as it is a retrospective study built on all reported cases of CO poisoning in South Korea from 2002 to 2017. Another strength is that the comparability was improved by selecting controls that were matched by sex and age. Additionally, it was appropriate to explore the long-term cardiogenic effect by linking the data on causes of death from KoSTAT, excluding subjects who were presumed to have died directly from CO poisoning.

\section{Conclusions}

Our study showed an association between CO poisoning and increased IHD risk. IHD risk was the highest within 2 years after $\mathrm{CO}$ poisoning. Although risk decreased over time, it remained significant for 6 years or more, implying that people who experience $\mathrm{CO}$ poisoning might have a substantial long-term risk of developing IHD. This increased risk was more pronounced among the younger age group and the group with comorbid diseases. Although we observed increased IHD risk after CO poisoning, the exact mechanism of this association remains unclear. Further studies of the long-term effects of $\mathrm{CO}$ poisoning on the cardiovascular system and the underlying mechanisms are thus required.

Author Contributions: Conceptualization, Y.B. and K.K.; methodology, Y.B. and K.K.; software, K.K.; validation, K.B., J.-T.P., and W.-J.C.; formal analysis, Y.B.; investigation, K.K.; resources, K.K.; data curation, K.B.; writing-original draft preparation, Y.B.; writing-review and editing, J.-T.P. and K.K.; visualization, W.-J.C.; supervision, K.K.; project administration, K.K. All authors have read and agreed to the published version of the manuscript.

Funding: This research received no external funding.

Institutional Review Board Statement: The study was conducted according to the guidelines of the Declaration of Helsinki, and approved by the Institutional Review Board of the Gachon University Gil Medical Center (IRB No. GCIRB2019-021).

Informed Consent Statement: Patient consent was waived by the Institutional Review Board of Gachon University Gil Medical Center because researchers were provided with de-identified data only. 
Data Availability Statement: The data used in this study are available from the Korean National Health Insurance Service (KNHIS). However, these data require deliberation and approval by the KNHIS and can be assessed only through the local intra-network of the KNHIS.

Conflicts of Interest: The authors declare no conflict of interest.

\section{References}

1. Weaver, L.K. Carbon monoxide poisoning. Undersea Hyperb. Med. 2020, 47, 151-169. [CrossRef] [PubMed]

2. Guzman, J.A. Carbon monoxide poisoning. Crit. Care Clin. 2012, 28, 537-548. [CrossRef] [PubMed]

3. Weaver, L.K. Carbon monoxide poisoning. Crit. Care Clin. 1999, 15, 297-317. [CrossRef]

4. Ernst, A.; Zibrak, J.D. Carbon monoxide poisoning. N. Engl. J. Med. 1998, 339, 1603-1608. [CrossRef] [PubMed]

5. Kao, L.W.; Nanagas, K.A. Toxicity associated with carbon monoxide. Clin. Lab. Med. 2006, 26, 99-125. [CrossRef]

6. Satran, D.; Henry, C.R.; Adkinson, C.; Nicholson, C.I.; Bracha, Y.; Henry, T.D. Cardiovascular manifestations of moderate to severe carbon monoxide poisoning. J. Am. Coll. Cardiol. 2005, 45, 1513-1516. [CrossRef]

7. Prockop, L.D.; Chichkova, R.I. Carbon monoxide intoxication: An updated review. J. Neurol. Sci. 2007, 262, 122-130. [CrossRef]

8. Henry, C.R.; Satran, D.; Lindgren, B.; Adkinson, C.; Nicholson, C.I.; Henry, T.D. Myocardial injury and long-term mortality following moderate to severe carbon monoxide poisoning. JAMA 2006, 295, 398-402. [CrossRef]

9. Hsu, P.C.; Lin, T.H.; Su, H.M.; Lee, H.C.; Huang, C.H.; Lai, W.T.; Sheu, S.H. Acute carbon monoxide poisoning resulting in ST elevation myocardial infarction: A rare case report. Kaohsiung J. Med. Sci. 2010, 26, 271-275. [CrossRef]

10. Dileo, P.A.; Tucciarone, M.; Castro, E.R.; Guerrero, M. Late stent thrombosis secondary to carbon monoxide poisoning. Cardiovasc. Revascularization Med. 2011, 12, 56-58. [CrossRef] [PubMed]

11. Hocagil, H.; Tanrikulu, C.S.; Ülker, V.; Kaya, U.; Koca, L.; Hocagil, A.C. Asymptomatic myocardial injury in a low level of carbon monoxide poisoning. Eurasian J. Emerg. Med. 2015, 14, 91-93. [CrossRef]

12. Lee, F.Y.; Chen, W.K.; Lin, C.L.; Kao, C.H. Carbon monoxide poisoning and subsequent cardiovascular disease risk: A nationwide population-based cohort study. Medicine 2015, 94, e624. [CrossRef] [PubMed]

13. Seong, S.C.; Kim, Y.Y.; Khang, Y.H.; Park, J.H.; Kang, H.J.; Lee, H.; Do, C.H.; Song, H.J.; Bang, J.H.; Ha, S.; et al. Data resource profile: The National Health Information Database of the National Health Insurance Service in South Korea. Int. J. Epidemiol. 2017, 46, 799-800. [CrossRef]

14. Xue, X.; Agalliu, I.; Kim, M.Y.; Wang, T.; Lin, J.; Ghavamian, R.; Strickler, H.D. New methods for estimating follow-up rates in cohort studies. BMC Med. Res. Methodol. 2017, 17, 155. [CrossRef] [PubMed]

15. Kwak, K.; Kim, M.; Choi, W.J.; Ju, Y.S.; Park, J.T. Association Between Carbon Monoxide Intoxication and Incidence of Ischemic Stroke: A Retrospective Nested Case-Control Study in South Korea. J. Stroke Cerebrovasc. Dis. 2021, 30, 105496. [CrossRef]

16. Nielsen, V.G.; Arkebauer, M.R.; Vosseller, K. Redox-based thrombelastographic method to detect carboxyhemefibrinogenmediated hypercoagulability. Blood Coagul. Fibrinolysis 2011, 22, 657-661. [CrossRef]

17. Gawlikowski, T.; Gomolka, E.; Piekoszewski, W.; Jawien, W.; Undas, A. Acute CO poisoning is associated with impaired fibrinolysis and increased thrombin generation. Basic Clin. Pharmacol. 2013, 112, 352-356. [CrossRef]

18. Cho, Y.; Kang, H.; Oh, J.; Lim, T.H.; Ryu, J.; Ko, B.S. Risk of venous thromboembolism after carbon monoxide poisoning: A nationwide population-based study. Ann. Emerg. Med. 2020, 75, 587-596. [CrossRef]

19. Grieb, G.; Simons, D.; Piatkowski, A.; Altiok, E.; Eppstein, R.J.; Bernhagen, J.; Pallua, N. Carbon monoxide intoxication versus myocardial infarction: An easy diagnosis? Burns 2011, 37, e29-e31. [CrossRef] [PubMed]

20. Dziewierz, A.; Ciszowski, K.; Gawlikowski, T.; Rakowski, T.; Kleczyński, P.; Surdacki, A.; Dudek, D. Primary angioplasty in patient with ST-segment elevation myocardial infarction in the setting of intentional carbon monoxide poisoning. J. Emerg. Med. 2013, 45, 831-834. [CrossRef]

21. Chang, W.T.; Chang, C.L.; Ho, C.H.; Hong, C.S.; Wang, J.J.; Chen, Z.C. Long-term effects of unprovoked venous thromboembolism on mortality and major cardiovascular events. J. Am. Heart Assoc. 2017, 6, e005466. [CrossRef] [PubMed]

22. Essebag, V.; Platt, R.W.; Abrahamowicz, M.; Pilote, L. Comparison of nested case-control and survival analysis methodologies for analysis of time-dependent exposure. BMC Med. Res. Methodol. 2005, 5, 5. [CrossRef] [PubMed]

23. Kim, R.S. Analysis of nested case-control study designs: Revisiting the inverse probability weighting method. Commun. Stat. Appl. Methods 2013, 20, 455-466. [CrossRef]

24. Raub, J.A.; Mathieu-Nolf, M.; Hampson, N.B.; Thom, S.R. Carbon monoxide poisoning-A public health perspective. Toxicology 2000, 145, 1-14. [CrossRef]

25. Simons, L.A.; Simons, J.; Friedlander, Y.; McCallum, J.A. Comparison of risk factors for coronary heart disease and ischaemic stroke: The Dubbo Study of Australian Elderly. Heart Lung Circ. 2009, 18, 330-333. [CrossRef] [PubMed]

26. Palomeras Soler, E.; Casado Ruiz, V. Epidemiology and risk factors of cerebral ischemia and ischemic heart diseases: Similarities and differences. Curr. Cardiol. Rev. 2010, 6, 138-149. [CrossRef] [PubMed] 